\title{
Observações preliminares acerca das pesquisas em educação do Amazonas
}

\author{
GARCIA, Fabiane Maia (Manaus, Amazonas, Brasil) ${ }^{1 *}$ \\ YASUDA, Bruna Chizuka (Manaus, Amazonas, Brasil) ${ }^{2 *}$ \\ BENE, Leonel Elias (Manica, Moçambique) $3^{3^{* * x}}$ \\ 1 Universidade Federal do Amazonas, Programa de Pós-Graduação em Educação, \\ Curso de Graduação em Pedagogia \\ ${ }^{2}$ Universidade Federal do Amazonas, Programa Institucional de Bolsas de Iniciação Científica, \\ Curso de Graduação em Pedagogia \\ ${ }^{3}$ Universidade Púnguè, Extensão e Delegação de Tete, Curso de Graduação em Psicologia \\ ORCID ID: https://orcid.org/0000-0003-0121-0416* \\ ORCID ID: https://orcid.org/0000-0002-7944-9526** \\ ORCID ID: https://orcid.org/0000-0002-5293-8493*
}

\begin{abstract}
Resumo
O trabalho apresenta uma reflexão com base nos dados de uma pesquisa com resultados preliminares dos seus primeiros doze meses. Desse modo, a análise é parte do estudo "Aspectos epistemológicos e metodológicos da pesquisa em educação no Amazonas", que investiga as pesquisas em educação do Programa de Pós-Graduação em Educação da Universidade Federal do Amazonas, com foco nas questões epistemológicas e metodológicas. A pesquisa é de natureza qualitativa, fruto do levantamento das teses e dissertações na Biblioteca Digital de Teses e Dissertações da Universidade Federal do Amazonas do recorte temporal de 2013-2015. A análise corresponde a oito teses disponíveis on-line, que colocam como centralidade a fundamentação teórica presente nos trabalhos disponíveis, com a análise da origem geográfica das obras listadas que deram alicerce para uma reflexão sobre o colonialismo científico. Assim, identificaramse pesquisadores de distintos contextos, destacando o orientador, os demais docentes do Programa de Pós-Graduação em Educação da Universidade Federal do Amazonas e as produções específicas da América Latina.
\end{abstract}

\section{Palavras-chave}

Pesquisa. Educação. Colonialismo.

\section{Preliminary observations on colonialism in Amazon education research}

\begin{abstract}
The work presents a reflection on the data of a research, considering the results of its first twelve months. Thus, the analysis is part of the study "Epistemological and Methodological Aspects of Research in Education in Amazonia" that investigated the research in education of the Postgraduate Program in Education of the Federal University of Amazonas, focusing on epistemological issues and methods. The research is qualitative in nature, the result of the survey of theses and dissertations in the Digital Library of Theses and Dissertations of the Federal University of Amazonas within the time frame between 2013 and 2015. The research was done with the eight theses available online, centering on their theoretical frame, based on the analysis of the geographic origin of the listed works that gave rise to a reflection on scientific colonialism. In this way, we identified researchers from different contexts, with regard to the advisor, other professors from Postgraduate Program in Education
\end{abstract}

Educação \& Formação, Fortaleza, v. 5, n. 14, p. 36-53, maio/ago. 2020

DOI: https://doi.org/10.25053/redufor.v5i14mai/ago.1706

http://seer.uece.br/redufor 
of the Federal University of Amazonas and the specific productions from Latin America.

\title{
Keywords
}

Research. Education. Colonialism.

\section{Observaciones preliminares sobre la investigación educativa en la Amazonía}

\begin{abstract}
Resumen
El trabajo presenta una reflexión basada en datos de una encuesta con resultados preliminares de sus primeros doce meses. Por lo tanto, el análisis es parte del estudio "Aspectos epistemológicos y metodológicos de la investigación en educación en Amazonas", que trata de la investigación educativa en el Programa de Posgrado en Educación de la Universidad Federal de Amazonas, centrándose en cuestiones epistemológicas y metodológicas. La investigación es de naturaleza cualitativa, resultado de la encuesta de tesis y disertaciones en la Biblioteca Digital de Tesis y Disertaciones de la Universidad Federal de Amazonas en el período 2013-2015. El análisis corresponde a ocho tesis disponibles en línea, que se centran en los fundamentos teóricos presentes en los trabajos disponibles, con el análisis del origen geográfico de los trabajos enumerados que proporcionaron la base para una reflexión sobre el colonialismo científico. Así, se identificaron investigadores de diferentes contextos, destacando el orientador, los otros profesores del Programa de Posgrado en Educación de la Universidad Federal de Amazonas y las producciones específicas de América Latina.
\end{abstract}

Palabras clave

Ciencia. Educación. Colonialismo.

\section{Introdução}

O crescimento das pesquisas educacionais no Brasil deu-se a partir de 1970 com a criação e expansão dos cursos de pós-graduação. O foco desses cursos estava voltado para a formação para a docência e a investigação, caracterizadas pela concentração de dissertações e teses que constituíam o testemunho da elaboração sistemática de conhecimentos na área de educação (BENITE, 2009).

Para Fávero (2009), o processo de expansão dos Programas de Pós-Graduação em Educação ocorreu em dois movimentos concomitantes no início de 1990, relacionados ao episódio anteriormente citado. O primeiro é que, com a expansão dos cursos de pós-graduação, esperava-se maior consolidação da área, e o segundo foi com a vinda de uma segunda expansão dos cursos, em especial das regiões Norte e Nordeste do país. Nesse contexto, havia o receio de que os novos 
cursos percorressem os mesmos erros dos programas pioneiros, como o de ter professores de áreas diversas que não a de educação, e, por isso, não propusessem temas e problemas do campo educacional.

Desse modo, com o crescimento dos estudos no campo da Educação, supõese a necessidade de entender como está sendo organizado e sistematizado esse processo. Segundo André (2007), nos últimos 20 anos, devido à expansão da pósgraduação, houve mudanças nos temas, nos problemas, nos referenciais teóricos, nas abordagens metodológicas, assim como também nos contextos de produção dos trabalhos.

Como parte do cenário descrito, o Programa de Pós-Graduação em Educação (PPGE) estabeleceu-se na Universidade Federal do Amazonas (UFAM) em 1986, com a parceria entre a Faculdade de Educação (Faced) e o antigo Instituto de Ciências Humanas e Letras (ICHL). E, transcorridos mais de trinta anos, o Programa consolidou-se na oferta de mestrado e doutorado, os quais até os meados de 2018 formaram cerca de 426 mestres e 30 doutores, segundo consta no próprio site da instituição (UFAM, 2018). Assim, a consolidação do PPGE tomou como referência o conhecimento da realidade da Região Amazônica, além de seus desafios no âmbito educacional, promovendo o diálogo entre os diversos conhecimentos, de modo a se articular os espaços para as discussões e para as suas divulgações (BRITO, 2016).

De acordo com informações disponíveis na Plataforma Sucupira referentes ao ano de 2017, disponíveis na Coleta Capes (BRASIL, 2018), o programa estabeleceu-se com o núcleo temático Educação, Culturas e Desafios Amazônicos para expressar a complexidade, a emergência e o consequente desafio de formar mestres e doutores em uma região com aspectos geográficos, políticos e históricos muito próprios e que se chocam com o conceito e com processos de desenvolvimento estabelecidos nacionalmente. Desse modo, o PPGE foi o pioneiro na formação de profissionais da Região Norte, sendo, até o ano de 2003, o único programa de pós-graduação reconhecido pela Coordenação de Aperfeiçoamento de Pessoal de Nível Superior (Capes). 
O percurso histórico de consolidação do PPGE no contexto amazônico estabeleceu-se a partir de ações conjuntas que foram realizadas pelo corpo docente e discente. Merece destaque a presença de egressos, que atualmente representam um pouco mais de $30 \%$ de docentes do programa, como consta ainda na Coleta Capes (BRASIL, 2018). A presença dos egressos no programa reforça a ideia de que a formação de novos pesquisadores é um desafio necessário no interior da própria universidade para estabelecer condições mínimas para sua consolidação. Nesse caso, a iniciação científica na UFAM é parte integrante da formação científica desenvolvida nos cursos de graduação com o Programa Institucional de Bolsas de Iniciação Científica (Pibic), sendo regido pela Resolução no 040/2012, do Conselho de Ensino, Pesquisa e Extensão (Consepe). Até o ano de 2018, já foram realizadas 8.590 pesquisas vinculadas ao Pibic, correspondentes aos campi da capital e do interior. Dentre elas, cerca de 1.378 são da área de Ciências Humanas, contabilizadas a partir de 2008, pois é o período em que a gestão dos projetos passa a ser realizada pela Plataforma Lira. Tal ação possibilita a verificação dos dados mencionados, conforme dados disponibilizados pela Pró-Reitoria de Pesquisa e Pós-Graduação (Propesp) da UFAM por meio do protocolo de no 23480027119201815, realizado no Portal da Transparência - e-Sic.

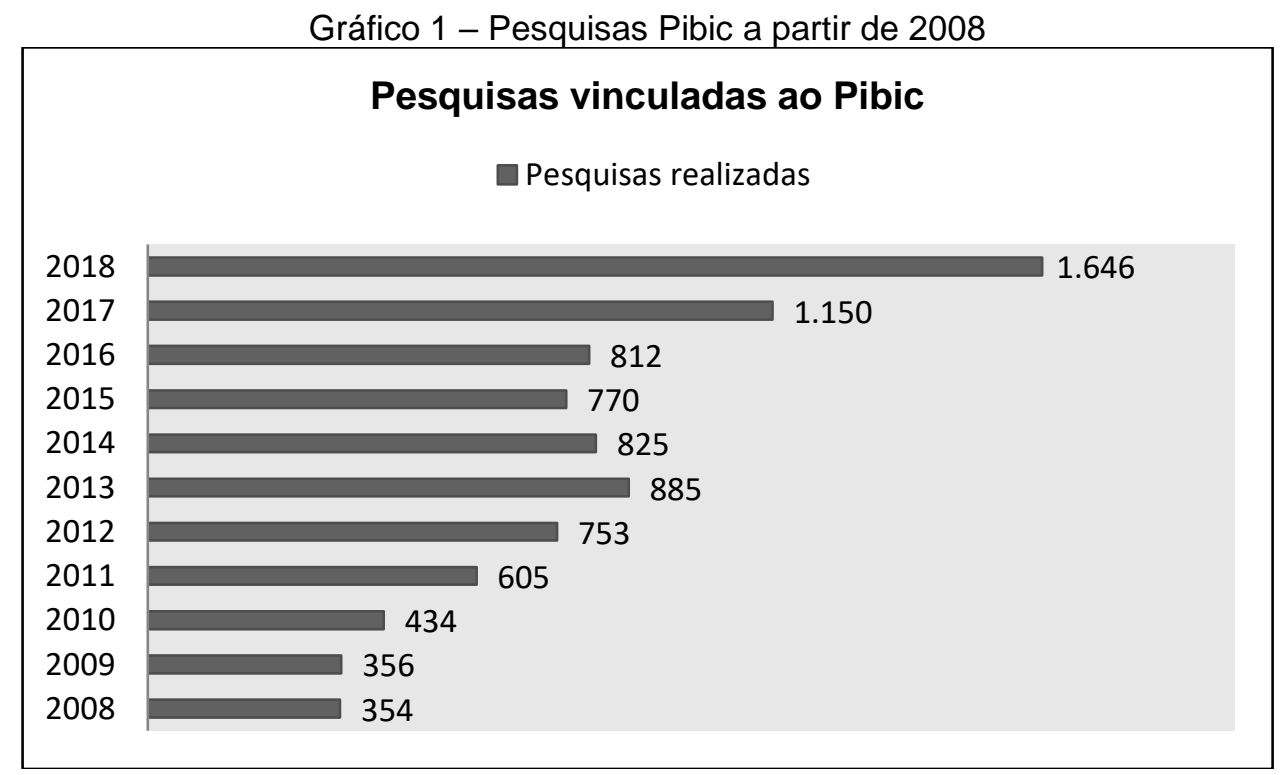

Fonte: Construído pelos autores com dados da Propesp-UFAM.

Educação \& Formação, Fortaleza, v. 5, n. 14, p. 36-53, maio/ago. 2020

DOI: https://doi.org/10.25053/redufor.v5i14mai/ago.1706

http://seer.uece.br/redufor 
Gráfico 2 - Pesquisas Pibic na área de Ciências Humanas a partir de 2018

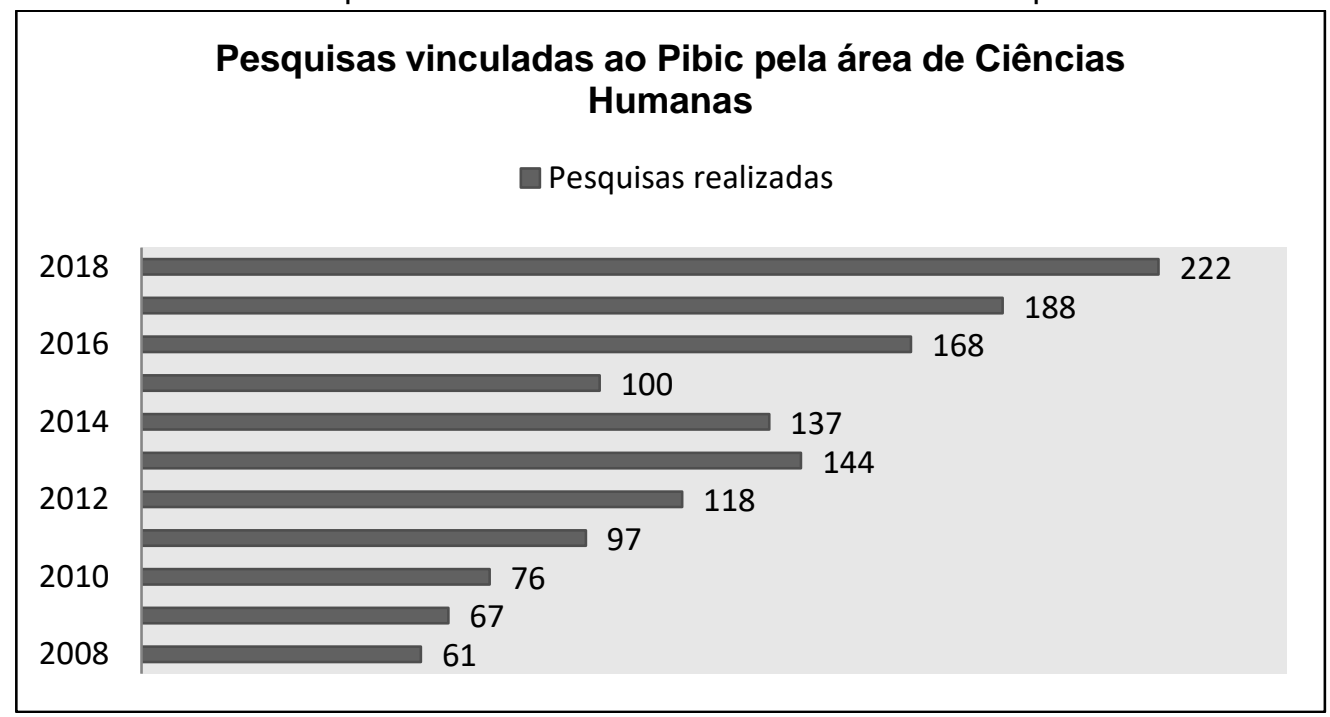

Fonte: Construído pelos autores com dados da Propesp-UFAM.

De acordo com os gráficos anteriores, foi possível identificar o crescimento gradual de pesquisas vinculadas à iniciação científica. Em relação ao ano inicial de registro, 2008, apenas em 2014 e 2015 houve redução no total de pesquisas, crescendo paulatinamente a partir de 2016 e tendo um salto qualitativo em 2018, momento em que o quantitativo dobrou em relação a 2015 e quadriplicou em relação ao primeiro registro.

O Pibic, dentre os seus objetivos, busca despertar o interesse científico de estudantes em nível de graduação, por meio da participação deles em projetos de pesquisa; promover o acesso e a aproximação do discente ao contexto científico; estimular os pesquisadores na inserção dos discentes quanto às atividades tecnológicas, artístico-culturais e científicas da universidade (UFAM, 2018).

O crescimento do Pibic é parte do fortalecimento da pesquisa na região, como um elemento institucional que integra o seu Plano de Desenvolvimento Institucional (PDI) 2016/2025 (UFAM, 2016). No referido plano, a UFAM reafirma seu foco na pesquisa, que se apresenta na busca de excelência no ensino de pós-graduação, na expansão dos cursos de pós-graduação, no estímulo à pesquisa, nas parcerias de fomento à pesquisa e na internacionalização da pesquisa como política institucional.

É nesse contexto institucional que o projeto de pesquisa intitulado "Aspectos epistemológicos e metodológicos da pesquisa em educação no Amazonas" propôs-se a investigar as pesquisas em educação. Por uma questão de recorte e de opção metodológica, a pesquisa refere-se apenas aos estudos desenvolvidos no interior do PPGE 
da UFAM. Como parte de sua proposta, o presente artigo objetiva apresentar os resultados referentes a alguns dados coletados nas teses defendidas no período de 2013 a 2015 e disponíveis on-line no Banco de Teses e Dissertações da universidade. O recorte temporal foi definido a partir de 2013, pois corresponde ao início da primeira avaliação quadrienal dos programas pela Capes, e - o mais importante - foi o momento em que o PPGE-UFAM foi avaliado pela primeira vez como programa, e não apenas como curso de mestrado.

\section{Metodologia}

O estudo sobre os aspectos epistemológicos e metodológicos da pesquisa em educação no Amazonas foi um estudo vinculado ao Pibic (2017/2018). Configurou-se metodologicamente com base em dois ângulos: o primeiro orientou-se pelos objetivos que caracterizam uma natureza explicativa, pois analisou os fatores condicionantes e contribuintes para a ocorrência de um determinado fenômeno. Conforme Gil (2008), esse é o tipo propício para conhecer uma dada realidade, porque explica a razão, a causa das coisas; o segundo ângulo manifestou-se em procedimentos técnicos - catalogação dos trabalhos e identificação quanto às temáticas, às áreas definidas pela Capes, às linhas de pesquisa e à abordagem metodológica, culminando em duas tabelas - tipificando o estudo em uma pesquisa documental, pois os documentos - teses e dissertações (PPGE) - que foram usados como bases não receberam tratamento analítico em sua integralidade ou conteúdo propriamente dito.

A pesquisa está enquadrada a esse segundo ângulo, pois, a princípio, foi realizada a catalogação das teses e dissertações publicadas no PPGE da UFMA dos anos de 2013 a 2014. E, posteriormente ao levantamento, foram elaboradas duas tabelas uma para as dissertações e a outra para as teses -, que tipificaram os trabalhos quanto às suas temáticas, às áreas definidas pela Capes, às linhas de pesquisas e às abordagens metodológicas. Vale destacar a mudança do critério de temporalidade inicialmente estabelecido em relação às teses, pois foi encontrada apenas uma, referente ao ano de 2014. Tal fato motivou o alargamento para o ano de 2015, integralizando, assim, oito teses. Apesar do número reduzido de teses, o quantitativo representa a totalidade dos trabalhos existentes no período e, como pesquisa qualitativa, o quantitativo não se configura como limitador para a análise proposta. No total, foram elaboradas três tabelas: 
as duas primeiras correspondem aos objetivos traçados inicialmente no projeto, construídas a partir de leituras das produções de Marlí André (2001, 2007) - mais especificamente a "Pesquisa em educação: buscando rigor e qualidade", que indica alguns aspectos da pesquisa que historicamente se modificaram, como os temas e as abordagens metodológicas, estes que compõem a estrutura das tabelas.

O preenchimento das tabelas foi realizado por meio da leitura dos resumos dos trabalhos analisados, que buscou identificar a temática, o enquadramento nas áreas definidas na Planilha Capes, linhas de pesquisa e abordagem metodológica. No tocante às temáticas, estas foram determinadas pelas palavras-chave indicadas nos próprios resumos. Já na definição das áreas previstas pela Capes, houve a identificação de duas ou mais áreas em um único trabalho, fato que justificou a opção pelo enquadramento a partir da linha de pesquisa indicada em cada tese. A linha de pesquisa foi determinada a partir da vinculação do orientador do trabalho analisado em relação às linhas existentes no PPGE. Por fim, os aspectos da abordagem metodológica, assim como da abordagem temática, foram extraídos com base no que os mestrandos e doutorandos definiram nos resumos analisados.

Quando o resumo não foi suficiente para o enquadramento anteriormente descrito, houve a necessidade da ampliação da leitura para os capítulos que correspondiam somente às metodologias. O referido procedimento foi adotado tanto nas dissertações quanto nas teses, de modo a padronizar a ação da pesquisa para atender ao aspecto da abordagem metodológica.

Além das leituras, os processos de orientação foram fundamentais para as opções e encaminhamentos adotados em relação à busca das informações, análise e interpretação dos resultados. Como parte desse momento, foi construído um caderno de orientação, que, além dos encaminhamentos, também registrava reflexões, dúvidas e avanços identificados no percurso da pesquisa. Nesse caso, algumas opções metodológicas se constituíram como parte do estudo, sem que necessariamente estivessem previstas ou determinadas. A sistematização dos dados em tabelas e o enquadramento das temáticas em áreas definidas pela Capes refletem o processo descrito, pois resultou da orientação e dinâmica da própria pesquisa.

Em realidade, na iniciação científica, em alguns momentos percebemos que as leituras e o projeto inicial não dão conta da complexidade vivenciada. No caso das 
temáticas, inicialmente a referência eram os estudos de André $(2001,2007)$, que norteavam o estudo, mas o conjunto proposto não conseguia enquadrar alguns trabalhos de acordo com as temáticas propostas, pois a produção do PPGE-UFAM apresenta temas transversais e específicos, fato equacionado ao tomar como referência a linha de pesquisa do orientador. A maioria dos trabalhos não apresentava textualmente a identificação de linha do programa.

Como mencionado anteriormente, foram elaboradas três tabelas. A terceira é referente somente às teses como um desdobramento da pesquisa, identificando se as produções citavam trabalhos de pesquisadores do PPGE e do orientador e se continham referências local, nacional e internacional, com destaque para produções da América Latina. Tais aspectos foram advindos de uma preocupação adicional que surgiu no desenrolar do estudo.

A pesquisa usou constantemente recursos vinculados às tecnologias da informação e comunicação. Nesse percurso, destacamos a catalogação na Biblioteca Digital de Teses e Dissertações da UFAM e o Portal da Transparência - e-Sic. Assim, confirmamos o uso determinante de tecnologia digital, como as fontes de acesso livre a periódicos on-line, o que permitiu a ampliação do acesso às produções que contribuíram para a fundamentação deste estudo. Desse modo, é notável como as tecnologias digitais vêm compondo de forma mais presente a produção dos conteúdos de diversas pesquisas no campo das Ciências Sociais e Humanas.

É essa perspectiva de ampliação do acesso às produções on-line que o estudo passou a assumir em relação às produções do PPGE e da América Latina, já que, a partir do uso da internet, esperávamos a maior possibilidade de circulação dessas produções e consequentemente seu uso, formalmente indicado nas listas de referências das teses, equiparando às de espaços geograficamente privilegiados e, desse modo, atingindo nível mais significativo no âmbito das produções acadêmicas.

\section{Resultados e discussão}

O cronograma para o desenvolvimento do estudo estabelecia quatro meses destinados à leitura e à análise bibliográfica, mas, com o andamento da pesquisa e das orientações, foi perceptível que a fundamentação do tema é uma atividade indissociável 
das demais fases estipuladas. Consequentemente a própria condução metodológica apresentou-se como um resultado importante, pois configurou-se como uma experiência para o exercício do que teoricamente se apresenta como característica do desenvolvimento das pesquisas em educação.

Assim, a iniciação científica converteu-se em uma atividade fundamental para entender e efetivar questões vinculadas ao eixo da pesquisa definido como parte da tríade ensino, pesquisa e extensão, necessária à formação de pedagogos na UFAM, pois, dentre as competências e habilidades desse profissional, pressupõe-se que, ao final da graduação, ele seja capaz de "[...] articular ensino e pesquisa na produção do conhecimento e da prática pedagógica" (UFAM, 2012a, p. 13). De maneira contínua, processual e integrada, a fundamentação teórica e bibliográfica amparou-se metodologicamente nos autores que constituíram inicialmente a proposta do projeto, como André $(2001,2007)$ e Gamboa (1998, 2013). Os estudos de André contribuíram para orientar o entendimento do contexto das pesquisas em educação no Brasil, referente à expansão dos programas de pós-graduação, juntamente com Benite (2009) e Fávero (2008).

As pesquisas também foram associadas e corroboradas pela perspectiva da busca do rigor e qualidade das produções propostas por Gamboa (1998, 2013), como fomento para a reflexão metodológica e epistemológica a respeito das produções, em companhia de autores como Gatti (2013), Gouveia (2005) e Mello (1983).

Ao longo das etapas, outros autores foram compondo o corpo da fundamentação do estudo, como Quijano (2005) e Santos (2002, 2007), advindos tanto da orientação quanto do processo de autonomia que devem ser premissas para aqueles que já na graduação se dedicam ao processo de pesquisa.

Em relação à catalogação das teses e dissertações do recorte temporal de 2013 a 2014, foram identificadas na Biblioteca Digital de Teses e Dissertações da UFAM 27 dissertações e uma tese de 2014. De imediato, percebeu-se que apenas uma tese não seria suficiente para a análise proposta. A existência da única tese reside no fato de o PPGE em 1998 - dois anos após a realização da sua primeira seleção para o doutorado - ter sido suspenso em consequência de uma avaliação da Capes (BRITO, 2016). Assim, a oferta do doutorado foi retomada somente no ano de 2010, após a ampliação da rede, que resultou na defesa de novas teses a partir de 2014, motivo pelo qual se 
ampliou o recorte do estudo para o ano de 2015, em relação às teses, totalizando, assim, oito trabalhos para a análise.

A partir dos trabalhos disponíveis e das referências indicadas, construiu-se uma matriz de análise representada por duas tabelas - uma para cada modalidade -, que tipificaram dissertações e teses quanto à temática preponderante, à área definida pela Capes, à linha de pesquisa e à abordagem metodológica. Essa atividade atendeu diretamente ao objetivo proposto para a iniciação científica em relação às questões epistemológicas e metodológicas da pesquisa em educação no PPGE, sem que isso seja elemento de análise neste trabalho.

Tabela 1 - Dissertações (2013-2014)

\begin{tabular}{c|c|c|c|c|c|c|c|c|c}
\hline \multirow{2}{*}{ Linha } & \multirow{2}{*}{ Temática } & \multicolumn{2}{|c|}{ Fins } & \multicolumn{3}{c|}{ Natureza } & \multicolumn{3}{c}{ Enfoques } \\
\cline { 3 - 10 } & BIBL. & CAMP. & QL. & QT. & QL./QT. & POS. & FEN. & M.H.D. \\
\hline 1 & $\begin{array}{c}\text { Identidade } \\
\text { cultural (4/7) }\end{array}$ & - & $7 / 7$ & $6 / 7$ & - & $1 / 7$ & - & $1 / 7$ & - \\
\hline 2 & $\begin{array}{c}\text { Políticas } \\
\text { públicas (5/11) }\end{array}$ & $5 / 11$ & $6 / 11$ & $9 / 11$ & - & $2 / 11$ & - & - & $4 / 11$ \\
\hline 3 & $\begin{array}{c}\text { Formação } \\
\text { docente (4/6) }\end{array}$ & $1 / 6$ & $5 / 6$ & $6 / 6$ & - & - & - & $1 / 6$ & $1 / 6$ \\
\hline 4 & $\begin{array}{c}\text { Educação } \\
\text { especial (2/3) }\end{array}$ & $3 / 3$ & - & $3 / 3$ & - & - & - & - & $1 / 3$ \\
\hline
\end{tabular}

Antes de apresentar a segunda tabela, referente às teses, é necessário esclarecer que o PPGE, ao ofertar o doutorado, possui apenas duas linhas de pesquisa, pois as quatro linhas do mestrado são integradas e transformadas nas linhas 2 e 3 . Assim, a linha 2 do doutorado integra a ementa da linha 4 do mestrado, enquanto a linha 3 integra a linha 1 do mestrado.

Tabela 2 - Teses (2014-2015)

\begin{tabular}{c|c|c|c|c|c|c|c|c|c}
\hline \multirow{2}{*}{ Linha } & \multirow{2}{*}{ Temática } & \multicolumn{2}{|c|}{ Fins } & \multicolumn{3}{c|}{ Natureza } & \multicolumn{3}{c}{ Enfoques } \\
\cline { 3 - 10 } & BIBL. & CAMP. & QL. & QT. & QL./QT. & POS. & FEN. & M.H.D. \\
\hline 1 & Diversos (3) & $1 / 3$ & $2 / 3$ & $3 / 3$ & - & - & - & - & - \\
\hline 2 & $\begin{array}{c}\text { Formação } \\
\text { docente (4/5) }\end{array}$ & $1 / 5$ & $4 / 5$ & $4 / 5$ & - & $1 / 5$ & - & - & $1 / 5$ \\
\hline
\end{tabular}

Fonte: Construída pelos autores com base no levantamento das teses.

No processo de tipificação das produções existentes no PPGE realizado com base na leitura de parte de dissertações e teses, percebeu-se pouca referência às 
pesquisas desenvolvidas no próprio PPGE e uma quase ausência de menção aos trabalhos publicados pelos docentes do programa. De fato, este artigo também é motivado por essa preocupação adicional, pois, mesmo não sendo inicialmente prevista, a situação evidenciada faz parte de um cenário importante na história dos programas em educação no Brasil, vinculada à questão da produção científica que se impõe como principal critério de qualidade aos programas de pós-graduação e à relação de subalternidade científica das produções existentes na Região Norte do Brasil.

Nesse contexto, o estudo buscou identificar quais as bases teóricas presentes na lista de referências bibliográficas de todas as teses. Isso parte da ideia de que as pesquisas no PPGE-UFAM sistematizam uma forma de entender e explicar a realidade educativa presente no contexto amazônico. Nessa interpretação e compreensão da educação na Amazônia, era de se supor a existência de uma base teórica nacional e internacional, como parte do diálogo necessário, mas que, pautada pela independência e autonomia em relação àquilo que nos caracteriza e identifica, privilegiasse autores e produções que se dedicam à pesquisa na Região Norte. Contudo, ao organizar as informações para o quadro de análise proposto, segundo os objetivos do estudo, tornava-se evidente a reduzida presença de produções científicas locais.

Assim, a terceira tabela buscou evidenciar o uso de obras do orientador de cada tese, de outros pesquisadores do PPGE, de produção do estado do Amazonas produção local -, de produção nacional, internacional e da América Latina, nas oito teses. Foi a partir dessa última tabela especificada que se optou por apresentar, neste momento, a análise prévia dos dados obtidos, pois o propósito é o de indicar apenas os resultados dos desdobramentos da pesquisa.

Tabela 3 - Desdobramentos da pesquisa

\begin{tabular}{c|c|c|c|c|c}
\hline \multicolumn{5}{c}{ Teses 2014-2015 } \\
\hline 8 Trabalhos & \multicolumn{4}{c}{932 Referências } \\
\hline Orientador & $\begin{array}{c}\text { Pesquisadores } \\
\text { do PPGE }\end{array}$ & Prod. Nac. & Prod. Loc. & Prod. Int. & $\begin{array}{c}\text { Prod. Am. } \\
\text { Lat. }\end{array}$ \\
\hline $\begin{array}{c}5 \\
(50 \%)\end{array}$ & $(62,5 \%)$ & $\begin{array}{c}585 \\
(62,76 \%)\end{array}$ & $\begin{array}{c}88 \\
(9,44 \%)\end{array}$ & $\begin{array}{c}248 \\
(26,60 \%)\end{array}$ & $\begin{array}{c}11 \\
(1,18 \%)\end{array}$ \\
\hline \multicolumn{6}{c}{ Fonte: Construída pelos autores. }
\end{tabular}

Ao catalogar quantitativamente o número e a característica das referências presentes nas teses, observou-se o baixo quantitativo de teses que citaram trabalhos da 
América Latina. A opção por salientar pesquisadores locais e da América Latina em separado da produção nacional e internacional é efetivada a partir da percepção de que as pesquisas desenvolvidas no programa parecem reforçar um processo de colonização científica. Assim, das oito teses, quatro fazem alusão a obras do próprio orientador e cinco outras referenciam produções internas ou diretamente vinculadas ao PPGE. De forma bruta, havia uma presença de referenciais do PPGE em pelo menos $75 \%$ das teses defendidas e catalogadas, mas essa relação se torna residual ao se considerar que foram identificadas um total de 932 referências usadas nas oito teses.

Do total das referências identificadas, apenas 88 produções são do estado do Amazonas, ou seja, apenas $9,44 \%$ do total, para uma maioria das obras de outras regiões, que representaram cerca de $62,76 \%$, ou 585 produções. As demais referências representam a produção científica internacional, com cerca de $26,60 \%$ destas, correspondendo a 248. No campo internacional, considerou-se significativa a localização geográfica e política da Amazônia, sendo importante identificar o diálogo das produções com pesquisas desenvolvidas no interior da América Latina, mas foram registradas apenas 11 obras - dentre os países, identificaram-se Colômbia e Cuba, cada um com duas obras; México e Argentina, cada um com três obras; e Panamá, com apenas uma obra. Isso constitui $1,18 \%$ das referências.

Os totais dispostos são representativos em relação ao debate estabelecido por Santos (2007) acerca da subalternização de determinados saberes em relação a outros, estes considerados como os únicos relevantes para a sociedade. E esse fato é justificado devido à nossa sociedade ser marcada pelo pensamento abissal, que:

\footnotetext{
Consiste num sistema de distinções visíveis e invisíveis, sendo que estas últimas fundamentam as primeiras. As distinções invisíveis são estabelecidas por meio de linhas radicais que dividem a realidade social em dois universos distintos: 0 'deste lado da linha' e o 'do outro lado da linha'. A divisão é tal que 'o outro lado da linha' desaparece como realidade, torna-se inexistente e é mesmo produzido como inexistente. (SANTOS, 2007, p. 71).
}

Essa característica do pensamento moderno ocidental pode ser equiparada ao identificado em relação aos dados resultantes das teses, pois os aspectos que envolviam o cenário regional e da América Latina foram os que apresentaram os menores quantitativos nos trabalhos analisados. 
Conforme Meneses (2008), atribuiu-se o termo "colonialidade do poder" às hierarquizações tanto de saberes como de sistemas econômicos e políticos, bem como à hegemonia das culturas eurocêntricas. A autora ainda exemplifica manifestações do tipo de colonialidade de caráter epistêmico, como é o caso da constante presença das reproduções de discriminações e de estereótipos. O referido termo retrata a dominação colonial que constituiu a América, mais especificamente a América Latina, resultando de forma decisiva em duas implicações da nova forma de poder - a colonialidade -, que instituiu implicitamente o padrão cognitivo, que concebia o conhecimento dos não europeus como ultrapassados e inferiores (QUIJANO, 2005).

Ainda conforme o autor, foi na América que as novas identidades históricas foram elaboradas, com base na ideia de raça e associadas às hierarquias, configurando também em relações de dominação, ou seja, a identidade racial transformou-se em critério de classificação social e principalmente legitimadora das relações de dominação, naturalizando-as.

A colonialidade definida anteriormente se aproxima da compreensão do modelo de racionalidade ocidental, amparado nas ideias de Santos (2002), que a denomina como razão indolente, com quatro formas diferentes de ocorrência: a razão impotente, a arrogante, a metonímica e a proléptica. Para a superação de tal modelo de racionalidade, o autor propõe a razão cosmopolita.

No entanto, a presença preponderante de referenciais nacionais e internacionais nas teses do PPGE distancia-se da razão cosmopolita e aproxima-se da razão metonímica, em que a lógica para o todo e as partes é regida por uma homogeneidade, que impede as partes de existirem sem a relação com o todo, e essa relação se dá pela dicotomia - o modo mais refinado de tal forma -, que é constituída pela junção da simetria com a hierarquia, como nos exemplos conhecimento científico/tradicional, civilizado/primitivo, homem/mulher, entre outros (SANTOS, 2002).

Os dados obtidos na análise das teses podem ser relacionados ao que Mourão (2018) denuncia na apresentação da publicação da Revista Amazônida do segundo semestre de 2017 a respeito da lógica produtivista a que os programas em educação estão submetidos, com avaliações distanciadas das especificidades das regiões brasileiras, sendo necessária a constante resistência e luta por parte dos programas. 
É necessário indicar que a razão metonímica requer três entendimentos, ainda conforme o autor: o de que a compreensão do mundo ocidental é limitada à da compreensão do mundo; o de que a compreensão gera e reconhece o poder social a partir de concepções de tempo e temporalidade; e o de que a racionalidade ocidental é caracterizada pela contração do presente e expansão do futuro.

Por meio dessas três compreensões, a razão cosmopolita deve buscar o trajeto contrário, isto é, expandir o presente e contrair o futuro, evitando, assim, o desperdício das produções. Além disso, para cada percurso é indicada uma sociologia, "[...] para expandir o presente, proponho uma sociologia das ausências; para contrair o futuro, uma sociologia das emergências" (SANTOS, 2002, p. 239). E, para que as experiências sociais sejam devidamente explicadas, o autor sugere o trabalho de tradução.

A razão que se afirma como exclusiva e homogênea se torna uma compreensão restrita do mundo, dentre as mais diversas existentes, e de si mesma. Ainda segundo Santos (2002), tal razão juntamente à proléptica são as que realmente fundam a racionalidade ocidental, devendo ser mais debatidas. Esse é o motivo de os questionamentos acerca das demais razões não promoverem maiores impactos.

Portanto, a pesquisa indica a existência da lógica do pensamento abissal que funda a racionalidade ocidental, agindo basicamente em excluir, tornar inexistente tudo aquilo que foge dos parâmetros hegemônicos por ela estabelecidos, atuando numa relação colonial, quer seja de dominação, quer seja de exploração.

Esse modelo de racionalidade ocidental gera um demasiado desperdício de diversos saberes que são desconsiderados pela sociedade, justificado pela razão indolente que assume como caráter de ordem a homogeneidade do todo e das partes. Desse modo, toda produção que fuja dessa lógica é excluída e afixada como inexistente para a sociedade ocidental, promovendo a desvalorização do que não se enquadra aos padrões hegemônicos.

Os resultados iniciais deste trabalho fazem parte de um conjunto de estudos que pretendem se aprofundar e articular o processo de oferta da pós-graduação na América Latina e em especial na Amazônia, tomando como base os desafios amazônicos que suscitam e apontam questões como a subalternidade vivida e reproduzida que nos aproximam de uma relação Sul-Sul que começamos a estabelecer. 


\section{Considerações finais}

$\mathrm{Na}$ análise pelas opções epistemológicas e metodológicas das teses e dissertações, a pesquisa identificou nas bases teóricas dos trabalhos o quantitativo diminuto de pesquisadores do estado, principalmente os vinculados ao programa em educação da UFAM. Um desdobramento da pesquisa que não poderia ser deixado de lado, visto que o PPGE da UFAM se compromete em discutir sobre o contexto amazônico, por isso presumia-se a consolidação de autores da região, fato que infelizmente não se apresentou.

A presença tímida das produções do estado do Amazonas e da América Latina, comparada ao quantitativo de obras citadas nos cenários nacional e internacional, dentre as oito teses analisadas, reafirma a denúncia de diversos estudiosos das Ciências Sociais e áreas afins quanto à existência de uma relação subalterna de saberes, fruto da relação de dominação imposta no período de colonização da América, que desencadeou a colonialidade do poder, perdurando até hoje.

É necessário, portanto, na luta por autonomia, a urgência em superar o modelo de racionalidade vigente, para um que parta do pressuposto da existência e da validade de vários conhecimentos, numa perspectiva que caminhe de modo contrário à homogeneidade e principalmente à subalternidade de saber.

A trajetória da presente pesquisa não se finda com este trabalho. Ela foi renovada. Para o seu segundo ano, buscará aprofundar quais as bases teóricas das pesquisas em educação do PPGE da UFAM, além de compará-las com as de programas notas seis e setes atribuídos pela Capes na última avaliação quadrienal.

Por fim, o estudo buscou, de forma inicial, contribuir para o fomento da discussão a respeito do que vem sendo utilizado como fundamentação teórica das pesquisas e quais as lentes que os pesquisadores do programa estão assumindo.

\section{Referências}

ANDRÉ, M. Pesquisa em educação: buscando rigor e qualidade. Cadernos de Pesquisas, São Paulo, n. 113, p. 51-64, 2001. Disponível em: http://www.scielo.br/scielo.php?pid=s010015742001000200003\&script=sci_abstract\&tlng=pt. Acesso em: 20 mar. 2020.

Educação \& Formação, Fortaleza, v. 5, n. 14, p. 36-53, maio/ago. 2020

DOI: https://doi.org/10.25053/redufor.v5i14mai/ago.1706

http://seer.uece.br/redufor 
ANDRÉ, M. Questões sobre os fins e sobre os métodos de pesquisa em Educação. Eletrônica de Educação, São Carlos, v. 1, n. 1, p. 119-131, 2007. Disponível em: http://www.reveduc.ufscar.br/index.php/reveduc/article/view/6. Acesso em: 20 mar. 2020.

BENITE, A. M. C. Considerações sobre o enfoque epistemológico do materialismo histórico dialético na pesquisa educacional. Revista Ibero-Americana de Educação, Araraquara, v. $50, \quad$ n. 4, p. 1-15, 2009. Disponível em: https://rieoei.org/historico/deloslectores/3024Benite.pdf. Acesso em: 20 mar. 2020.

BRASIL. Ministério da Educação. Plataforma Sucupira. Disponível em: https://sucupira.capes.gov.br/sucupira/. Acesso em: 9 jul. 2018.

BRITO, R. M. Os fios e as cores na rede de conhecimentos do PPGE: 31 anos de criação, 30 de funcionamento. Amazônida, Manaus, v. 1, n. 2, p. 3-11, 2016. Disponível em: http://www.periodicos.ufam.edu.br/index.php/amazonida/article/view/3769. Acesso em: 20 mar. 2020.

FÁVERO, O. Pós-Graduação em Educação: avaliação e perspectivas. Revista de Educação Pública, Cuiabá, v. 18, n. 37, p. 311-327, 2009. Disponível em: http://periodicoscientificos.ufmt.br/ojs/index.php/educacaopublica/article/view/482.

Acesso em: 20 mar. 2020.

GAMBOA, S. S. Epistemologia da pesquisa em educação. Campinas: Práxis, 1998.

GAMBOA, S. S. Tendências epistemológicas: dos tecnicismos e outros "ismos" aos paradigmas científicos. In: FILHO, J. C. S.; GAMBOA, S. S. (Org.). Pesquisa educacional: quantidade-qualidade. 8. ed. São Paulo: Cortez, 2013. p. 59-81.

GATTI, B. A. Pós-Graduação e pesquisa em Educação no Brasil, 1978-1981. Cadernos de Pesquisa, São Paulo, n. 44, p. 3-17, 2013. Disponível em: http://publicacoes.fcc.org.br/ojs/index.php/cp/article/view/1474. Acesso em: 20 mar. 2020.

GIL, A. C. Como elaborar um projeto de pesquisa. 3. ed. São Paulo: Atlas, 2008.

GOUVEIA, A. J. Algumas reflexões sobre a pesquisa educacional no Brasil. Revista Brasileira de Estudos Pedagógicos, Brasília, DF, v. 86, n. 2, p. 143-146, 2005. Disponível em: http://rbep.inep.gov.br/ojs3/index.php/rbep/article/view/1409. Acesso em: 20 mar. 2020.

MELLO, G. N. A pesquisa educacional no Brasil. Cadernos de Pesquisa, São Paulo, n. 46, p. 67-72, $1983 . \quad$ Disponível em: http://publicacoes.fcc.org.br/ojs/index.php/cp/article/view/1501. Acesso em: 20 mar. 2020.

MENESES, M. P. Epistemologias do Sul. Revista Crítica de Ciências Sociais, Coimbra, n. $\quad 80, \quad$ p. $5-10, \quad 2008.2$ Disponível em: http://periodicos.uem.br/ojs/index.php/EspacoAcademico/article/view/12314. Acesso em: 20 mar. 2020. 
MOURÃO, A. R. Em defesa da educação pública. Amazônida, Manaus, v. 2, n. 2, p. 1-3, 2018.

QUIJANO, A. Colonialidade do poder, eurocentrismo e América Latina. In: LANDER, E. (Org.). A colonialidade do saber: eurocentrismo e ciências sociais. Perspectivas latinoamericanas. Buenos Aires: Clacso, 2005. p. 107-130.

SANTOS, B. S. Para além do pensamento abissal: das linhas globais a uma ecologia de saberes. Novos Estudos, São Paulo, n. 79, p. 71-94, 2007. Disponível em: http://www.scielo.br/scielo.php?script=sci_arttext\&pid=S0101-33002007000300004.

Acesso em: 20 mar. 2020.

SANTOS, B. S. Para uma sociologia das ausências e uma sociologia das emergências. Revista Crítica de Ciências Sociais, Coimbra, n. 63, p. 237-280, 2002. Disponível em: https://journals.openedition.org/rccs/1285. Acesso em: 20 mar. 2020.

UFAM - Universidade Federal do Amazonas. Colegiado do Curso de Pedagogia. Projeto Político-Pedagógico do Curso. Manaus: UFAM, 2012a.

UFAM - Universidade Federal do Amazonas. Conselho de Ensino, Pesquisa e Extensão - Consepe. Resolução no 040/2012. Manaus: UFAM, 2012b.

UFAM - Universidade Federal do Amazonas. Programa de Pós-Graduação em Educação - PPGE. Site do PPGE da UFAM. Disponível em: http://www.ppge.ufam.edu.br/. Acesso em: 27 nov. 2018.

UFAM - Universidade Federal do Amazonas. Pró-Reitoria de Pesquisa e Pós-Graduação - PROPESP. Edital 004/2018. Manaus: UFAM, 2016.

UFAM - Universidade Federal do Amazonas. Pró-Reitoria de Planejamento e Desenvolvimento Institucional. Plano de Desenvolvimento Institucional: 2016-2025. Manaus: UFAM, 2016.

\section{Fabiane Maia Garcia (Manaus, Amazonas, Brasil)}

Universidade Federal do Amazonas (UFMA), Programa de Pós-Graduação em Educação, curso de graduação em Pedagogia

Docente do PPGE da UFAM - Linha de Educação, Políticas Públicas e Desenvolvimento Regional. Doutora em Educação pela Universidade de Minho - Portugal (2015), mestra em Sociedade e Cultura na Amazônia pela UFAM (2005), com graduação em Pedagogia pela também pela UFAM (1995). Professora adjunta III da UFAM. Coordenadora do PPGE e professora do curso de Pedagogia.

Contribuição de autoria: Orientou a escrita do texto e da pesquisa.

Lattes: http://lattes.cnpq.br/0062882509525303.

E-mail: fgarciaead@gmail.com. 


\section{Bruna Chizuka Yasuda (Manaus, Amazonas, Brasil) \\ Universidade Federal do Amazonas (UFMA), Programa de Pós-Graduação em Educação, curso de graduação em Pedagogia}

Estudante finalista do curso de Pedagogia da UFAM e bolsista da Fundação de Amparo à Pesquisa do Estado do Amazonas (Fapeam).

Contribuição de autoria: Desenvolveu o processo de recolha, tratamento e análise de dados.

Lattes: http://lattes.cnpq.br/1637899973985514.

E-mail: chizuka96@gmail.com.

\section{Leonel Elias Bene (Manica, Moçambique) \\ Universidade Púnguè (UniPúnguè), Extensão e Delegação de Tete, Curso de Graduação em Psicologia}

Professor da UniPúnguè - Extensão de Tete (ex-Universidade Pedagógica de Moçambique Delegação de Tete, extinta pelo Decreto no 2/2019, de 13 de fevereiro), atuando na graduação nas disciplinas de Psicologia do Desenvolvimento e da Aprendizagem, Orientação Escolar e Profissional. Áreas de interesse: Psicologia e Educação.

Contribuição de autoria: Apoiou a discussão do colonialismo presente na pesquisa.

E-mail: leonel.bene@gmail.com.

Editora responsável: Lia Machado Fiuza Fialho

Pareceristas ad hoc: Débia da Silva Sousa e Maria do Socorro de Braun

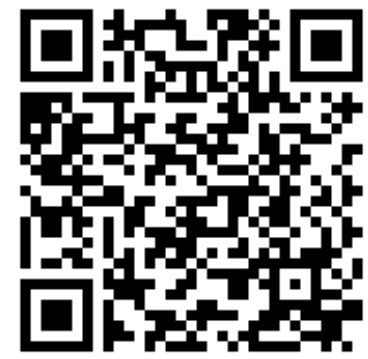

Recebido em 01ํ de setembro de 2019.

Aceito em 02 de janeiro de 2020. 